\title{
Designing Residential Buildings for Older People in China to Promote Ageing-in-place
}

\author{
Tulika Gadakari ${ }^{1}$, Jingjing Wang ${ }^{2}$, Karim Hadjir ${ }^{2}$, Junjie Huang ${ }^{2}$ \\ 1 School of Art and Design, \\ Coventry University, UK \\ 2 School of Architecture, \\ The University of Sheffield, UK \\ tulika.gadakari@coventry.ac.uk
}

\begin{abstract}
Ageing-in-place is the most common ageing model in China. Therefore, design of age-friendly residential buildings and neighbourhoods becomes an important factor leading to improvement in older people's health and quality of life. This paper presents the current situation of the ageing population in Chinese cities by qualitatively analysing existing literature, design standards and conducting stakeholder interviews to understand older people's housing choices and aims to identify physical design factors, challenges and potentials of residential design for older people. The findings will fill the knowledge gap of age-friendly residential models in China and guide better design to meet older people's needs.
\end{abstract}

Keywords: ageing; age-friendly design; residential building; spatial design

eISSN 2398-4279 @ 2018. The Authors. Published for AMER ABRA cE-Bs by e-International Publishing House, Ltd., UK. This is an open access article under the CC BY-NC-ND license (http://creativecommons.org/licenses/bync-nd/4.0/). Peer-review under responsibility of AMER (Association of Malaysian Environment-Behaviour Researchers), ABRA (Association of Behavioural Researchers on Asians) and cE-Bs (Centre for EnvironmentBehaviour Studies), Faculty of Architecture, Planning \& Surveying, Universiti Teknologi MARA, Malaysia.

DOI: https://doi.org/10.21834/ajqol.v3i13.158 


\subsection{Introduction}

The global population is undergoing a marked demographic shift, where older people will soon outnumber youth populations owing to increase in life expectancy, falling fertility rates, and lifestyle changes. The number of people aged 65 or older is projected to grow from an estimated 524 million in 2010 to nearly 1.5 billion in 2050, with most of the increase in developing countries. (World Health Organisation, 2011)

The number of people in China over the age of 65 are rising rapidly and are likely to grow from 123 million in 2011, 200 million in 2026, 300 million in 2038, to 330 million by 2050, with around 100 million over the age of 80 (World Health Organisation, 2011; United Nations, 2013; OECD, 2014). China is also witnessing key changes in family structures, urbanisation, education and increasing participation of women in the labour market. These shifts are challenging the traditional family-based care arrangement for older people and have direct consequences on access to social care, financial security and influence the quality of life. (Feng, 2014)

\subsection{Literature Review}

According to the National Bureau of Statistics of the People's Republic of China (2016), home-based ageing model is the most common in China. China has a long familistic history and people are keen to uphold the traditional practice of family-based care rooted in the ideological foundation of filial piety and mutual support, thus preferring to age-in-place (Zhou \& Walker, 2016). Ageing-in-place is defined as "remaining living in the community, with some level of independence, rather than in residential care" (Davey, de Joux, Nana, \& Arcus, 2004).

Pannell \& Blood (2012) and Torrington (2014) identify, mobility support, sensory support, support for cognitive failings and health and safety, as key while adapting homes or local neighbourhoods for older people to age-in-place. There is significant evidence that making homes more accessible, with better spatial configuration, can reduce the need for care, reduce falls, increase independence and improve quality of life (Iwarsson \& Ståhl, 2003; Best \& Porteus, 2016). Additionally optimising lighting, maintaining comfortable temperature, providing good outdoor spaces, views and tonal contrasts makes it comfortable, healthier and safer for older people (Roelofsen, 2014; Hussein, Omar, \& Ishak, 2016; Gupta, Barnfield, \& Gregg, 2017). Personalisation of space, use of design prompts, colours to 'theme' areas, meaningful artwork, pictorial signage and pictures can help orientate older people with cognitive impairments. An environment that is designed to be intuitive and easy to use can enable older people to experience a sense of competence, choice and control (Faith, Hadjri, Rooney, Twyford, 2016; Walker, 2017). In addition to design, the use of technology is actively enabling aspects of ageing-in-place (HACT, 2016; Agile Ageing Alliance, 2017).

Ageing-in-place has shown to have a positive correlation with health and well-being and sense of satisfaction and contentedness (Renaut, Ogg, Petite, \& Chamahian, 2015; Stones \& Gullifer, 2016; Dahlan \& Sultanlbrahim, 2017; Yousefi, Hosseini, Yazdanfar, \& NorouzianMaleki, 2017). Remaining in their own homes and communities helps in the maintenance of social connection and support from family and friends (Lawler, 2001; Muhammad, 2016; Zakariya, Harun, \& Mansor, 2016). Additionally, ageing-in-place is also an option to avoid the 
expensive choice of institutional care and is therefore favoured by policy makers, health providers, and by many older people themselves (World Health Organization, 2007).

Family structures and living arrangements greatly influence the area of homes in China. $49.4 \%$ of $60-70$ year olds co-reside with their children and this rises to $58 \%$ as people age over 80 years. (China Health and Retirement Longitudinal Study, 2013) From a sample size of 420 respondents, a family of two (43.3\%) is the most common type for older people, closely followed by the family of five (21\%) and four ( $18.1 \%)$. Older people living alone mainly occupy $50 \mathrm{~m}^{2}$ or less; a family of two usually occupies $50-100 \mathrm{~m}^{2}$; and a family of five usually occupies $100-150 \mathrm{~m}^{2}$. (Zhang, Liu, \& Qi, 2015) $5.2 \%$ of older people or couples occupy less than one room; $25.5 \%$ have one room; $24.5 \%$ have two rooms; $20.6 \%$ have three rooms; $14.3 \%$ have four rooms and $9.8 \%$ have five rooms (Li, 2010).

Currently there are a number of global building standards for inclusive design, which align with inclusion requirements and disability acts (Hadjri, Afacan, \& Gadakari, 2016). The latest design standard for older people in China titled 'Code for design of residential building for the aged' aims to meet older people's need for safety, accessibility, health, cost-effectiveness and environmental sustainability by employing 30 criteria under 5 categories of site and planning; public space; space within the dwelling unit; physical environment; and building equipment. (MOHURD \& AQSIQ, 2017)

\subsection{Methodology}

A list of academic researchers and practitioners who are experts in the field of ageing and have been involved in projects for older people in China was compiled. Nine experts agreed to be interviewed via telephone, which included: Professor (Social Science) and Associate Professor (Architecture), Tsinghua University, Beijing; Professor (Social Science), Chinese Academy of Sciences, Beijing; Professor (Interior Design) and Associate Professor (Environmental design), Beijing Union University, Beijing; Chief Designer (Interior and Product Design), Beijing; Design Director (Architect), China Construction Design International (CCDI), Shanghai; Chief Architect, Shanghai; and Architect, Hunan Province.

The interview questions were developed based on findings from the literature review and previous research by the authors. The interview schedule contained fourteen questions which are included in the Appendix. The semi-structured interviews were audio recorded, transcribed verbatim, translated from Chinese to English and thematically analysed.

The researchers familiarised themselves with the data, which involved reading and rereading the text to spot similarities, differences, and contrasts. Themes were established, reviewed and refined collaboratively between four members of the research team at regular meetings to ensure reliability, consistency, and to minimise bias.

\subsection{Results}

The interviewees gathered upon their knowledge and expertise as academic researchers and design practitioners to address the themes of design, spatial requirements, emotional factors and community as highly important factors to improve the future of age-friendly 
residential models in China to enable older people to age-in-place.

\subsection{Design}

Health and safety was unanimously prioritised as the most important factor to consider while designing for older people, followed by accessibility, sensory and cognitive factors. The common design factors highlighted by the experts, which enable ageing-in-place are thematically divided as follows:

Table 1. Design factors that enable ageing-in-place

\begin{tabular}{|c|c|c|c|c|}
\hline Accessibility & Sensory & Health \& Safety & $\overline{\text { Cognitive }}$ & $\overline{\text { Social }}$ \\
\hline Spacious rooms & Natural light & Anti-slip flooring & $\begin{array}{l}\text { Familiar } \\
\text { environment }\end{array}$ & $\begin{array}{l}\text { Community } \\
\text { centres }\end{array}$ \\
\hline $\begin{array}{l}\text { Wide cornidors and } \\
\text { doors }\end{array}$ & $\begin{array}{l}\text { Motion sensor } \\
\text { controled lights }\end{array}$ & $\begin{array}{l}\text { Design to prevent } \\
\text { falls }\end{array}$ & $\begin{array}{l}\text { Design to create } \\
\text { memory triggers }\end{array}$ & Activity areas \\
\hline Wheelchair ramp & $\begin{array}{l}\text { Close to floor } \\
\text { lighting at night }\end{array}$ & Rounded fumiture & $\begin{array}{l}\text { Photos of children, } \\
\text { memories, ewents }\end{array}$ & Religious buildings \\
\hline $\begin{array}{l}\text { Turning area for } \\
\text { wheelchairs }\end{array}$ & Ventilation & Large lifts & $\begin{array}{l}\text { Design for purpose } \\
\text { and routine }\end{array}$ & Public tolets \\
\hline $\begin{array}{l}\text { Modfications in } \\
\text { bathroom, toilat } \\
\text { and kitchen }\end{array}$ & Thermal comfort & $\begin{array}{l}\text { Dual opening } \\
\text { doors to prevent } \\
\text { locking in }\end{array}$ & $\begin{array}{l}\text { Community Senior } \\
\text { education } \\
\text { schernes }\end{array}$ & Public seating \\
\hline $\begin{array}{l}\text { Lowered furniture } \\
\text { heights }\end{array}$ & $\begin{array}{l}\text { Soothing colour } \\
\text { schemes }\end{array}$ & $\begin{array}{l}\text { Community Health } \\
\text { Care faclities }\end{array}$ & $\begin{array}{l}\text { Community library } \\
\text { \& theatre }\end{array}$ & Local amenities \\
\hline $\begin{array}{l}\text { Handrails and grab } \\
\text { bars }\end{array}$ & Acoustic materials & $\begin{array}{l}\text { Extra storage for } \\
\text { medicines }\end{array}$ & $\begin{array}{l}\text { Public spaces that } \\
\text { feel safe }\end{array}$ & Waking pathways \\
\hline Wak-in showers & Viaws & & & \\
\hline No threshoids & Indoor plants & & & \\
\hline $\begin{array}{l}\text { Automatic and } \\
\text { sliding doors }\end{array}$ & $\begin{array}{l}\text { Outdoor spaces } \\
\text { and landscaping }\end{array}$ & & & \\
\hline \multicolumn{5}{|l|}{$\begin{array}{l}\text { Comfortable stair } \\
\text { gradients }\end{array}$} \\
\hline $\begin{array}{l}\text { Flexibuity for future } \\
\text { home adaptations }\end{array}$ & & & & \\
\hline
\end{tabular}

All the experts responded that the building design standards for older people were important and guided their design process as well as their research, though they agreed that the current design standards in China were still at an early developmental stage and need to be more detailed; focus on older people's health and ergonomics; provide more information on assistive technologies; reflect more design flexibility; be sensitive to older people's needs and issues; and cater to the significant differences in climate and lifestyle.

Some experts believed that the Chinese government was implementing a number of effective policies in areas of foreign investment, pension system, vouchers and gift cards, support to build community centres, encouragement of public-private partnership models, job placements and postponement of retirement age. It was also added that the policies needed to be detailed, put into practice and the government needed to provide more community level care services, train care professionals and improve infrastructure. 
Some of the experts noted that though some old 6-7 storey buildings in China were being refurbished by adding lifts externally, there were issues with cost sharing, blockage of views and excessive noise. Limited space was also perceived as a barrier to refurbish buildings especially when surrounding buildings impacted access to natural light and ventilation. Most experts suggested that flexible design should be encouraged for future adaptability though they had struggled with the structural framework, which limited their design intentions of opening up interior spaces for better mobility and natural light. The experts noted that modifications in the bathroom such as replacing the bathtub with a walk-in shower and adding grab bars were most needed.

Assistive technology (AT) that assists during emergencies; monitors and reports health conditions; maintains improved indoor environmental quality; helps combat loneliness and social isolation; and assists with failing memory, by integrating with architectural and interior design was considered as an important part of the design. Although AT was perceived to be expensive and its affordability is a major issue hindering its uptake.

Most experts felt that a certain socio-economic section of Chinese older people could not afford refurbishment of their homes with their meagre pension and savings. At the same time, most experts concurred that there is a rising affluent middle class in China which can afford to spend money on home improvement but the consumer attitude of this older generation is very different and they are quite frugal.

\subsection{Spatial Requirements}

The experts were of the opinion that overcrowding was predominantly an urban issue. Most experts agreed that better design and innovative solutions would make a difference to the living environment in crowded homes. Three of the experts shared their experience of refurbishing small homes for older people where multifunctional furniture, well-designed storage, clearing out cluttered paths and improved natural light, were employed to improve accessibility, safety and the 'experience of the home'.

One of these experts introduced the concept of 'time sharing' where multiple spaces in the home can be used for different functions at different times of the day, by various family members, so as to promote multigenerational living. Most of the experts agreed that design which considered the different generations' varied lifestyle, promoted 'co-working' and communication were key to resolving multigenerational family conflicts. Differing sleeping patterns of the generations sharing a home were considered to be most disruptive. Providing better acoustics so that different generations could function without disturbing each other and be mindful of privacy was considered key by most experts.

The traditional courtyard housing model of China was considered a good example of human-centric design as it provides a balance of private-public space. Unfortunately, the experts noted that current mainstream housing in urban China is mainly mass housing which fails to satisfy the needs of older people. In such cases, some of the experts indicated that the onus of human-centred care would lie on better community design.

\subsection{Emotional factors}

All the experts unanimously agreed that architectural design which supported older people's 
physical and psychological needs and enabled them to function independently on a daily basis would be considered as human-centric design.

Experts suggested displaying photos of children, memorabilia, having pets and having space to engage in social activities as simple methods to reduce loneliness. Some experts recommended that instead of focusing on design for older people, designers should concentrate on lifetime housing which could be adaptable as people aged.

Usually Chinese older people do not want to move to care homes as they do not feel attached to the new surroundings, hence it was deemed very important by all experts that care homes employ a sensitive design approach to make older people 'feel at home'. Additionally, most experts reported that maintaining older people's dignity and privacy in a care home was key to making them feel comfortable. Two of the experts noted that the current care homes in China either felt like a 'hospital' or a 'hotel', i.e. they both lacked the intimate homely feeling and pleasant scale of a home.

Experts also suggested that older people in care homes should be allowed to bring their own furniture, memorabilia, reposition their décor and have freedom to personalise their space according to their needs and lifestyle. It was very important to provide private social spaces in care homes which could be used when family and friends visited.

\subsection{Community}

The experts concurred that designing a better community environment not only includes the physical aspects such as a barrier-free design, open spaces, walkways, public toilets and outdoor seating but also cultivating a sense of community. The experts recommended the use of design to create memory triggers by incorporating sensory elements such as colours, sounds, landscape, etc. Most experts agreed that the design of community spaces should be conducive to older people's social life, encourage activities and multigenerational interaction.

The experts shared that some well-organised communities were providing services to older people such as checking up on them socially, providing free telecare bracelets and large button telephones to contact during an emergency, help buying groceries and medicines and providing gym equipment in public parks. Additionally, it was reported that small-scale community run care homes were gaining popularity as older people preferred to live within their familiar community, near their children and friends, while enjoying the option to have care and health services.

The barrier with regards to community design as noted by most experts was the lack of space, limited resources and funding. One of the experts narrated that many of the developers in charge of community centres had built them in underground spaces. Such spaces were undesirable and largely unused by the community. It was felt that such situations could be remedied through government funding and strict policies and regulations.

\subsection{Discussion}

The interview results concur that ageing-in-place can be a viable housing choice for people 
in China for not only the physical but also the psychological needs of older people, such as companionship, family values, traditions, to be satisfied. The experts had similar views on what guided Chinese older people's housing choice and the following reasons were highlighted for ageing-in-place:

1) To save money as good care homes were unaffordable

2) Tradition of familial care and support

3) To live with family

4) Help raise grandchildren

5) Continue to live within their familiar home and community

6) Sense of independence, freedom and belonging

7) Care homes in China are not up to the standard

8) Societal pressure and embarrassment associated with moving to a care home

9) Children find visiting care homes too inconvenient

Though ageing-in-place is considered the future of ageing in China there were concerns raised about the level of support available and the limitations due to age and health. The interviews revealed current challenges which inhibited older people from ageing in their own homes and neighbourhoods, which included:

1) Crowded mass housing

2) External addition of lifts leads to blockage of views, excessive noise and reluctance among residents to share costs

3) Community design is hampered due to the lack of space, limited government funding and inadequate policies and regulations

4) Refurbishment of old residential buildings is difficult due to limited space, inadequate light and ventilation and structural inflexibility

5) Unwillingness of older people to engage in home refurbishment due to meagre pension and savings, conservative consumer attitude, lack of time and effort, saving money for their family and lack of awareness

6) AT is perceived to be expensive and its affordability is a huge hindrance to its uptake The experts also observed that there was some existing potential which needed to be further explored so as to enable older people to age-in-place better. These positives included the traditional Chinese courtyard housing model, effective government policies, services provided by the community and community run care homes.

\subsection{Conclusion}

The interview findings have revealed the challenges, potentials and needs of older people in China as experienced by the experts through their research as well as designing projects for older people in China. The findings of this research will help fill the knowledge gap present in the current housing models in China so that they can be significantly age-friendly and establish innovative design solutions which take into account the cultural, social, economic and political contexts. This research could potentially benefit a range of stakeholders, i.e. decision makers and local governments; architects, interior designers, product designers; health and social care professionals; and professionals from the AT industry, to guide better 
design and to meet older people's needs in the future.

To conclude, this research proposes some recommendations, which include:

1) Human centric design that promotes health and safety and is supportive of physical and psychological needs of older people

2) Traditional Chinese courtyard housing design with incorporation of new environmentallyfriendly technologies for better thermal comfort, lighting, acoustics, etc.

3) Detailed building design standards for older populations with focus on health and ergonomics; information on AT; design flexibility; sensitive to needs; and cater to the significant differences in the northern and southern parts of China

4) Encourage refurbishment of homes through government funding, subsidiaries and raising awareness of modern design and technologies

5) Improve crowded multigenerational homes through multifunctional furniture; multifunctional, co-working spaces; sensitive design for varied lifestyles and habits; better acoustics; features to improve natural light; well-designed storage; circulation spaces; and access to local community centres

6) Design to create memory triggers by incorporating sensory elements

7) Blend institutional aspects associated with age-friendly design with the rest of the décor

8) Create a familiar homely environment in care homes through an intimate and pleasant scale; casual dining areas with sofas and break out spaces; scope to personalise space with their own furniture, memorabilia, photos; and having pets

9) Improved community design with scope for social activities, multigenerational interaction, professional care, health care facilities, fitness facilities, cafes and food delivery

10) Integrate user-friendly assistive technologies (AT) with architectural and interior design

11) AT designed specifically for older people that is 'easy to use', meets all their needs and is not complicated to operate

12) AT that, assists during emergencies; monitors and reports health conditions; maintains improved indoor environmental quality; helps combat loneliness and social isolation; and assists with failing memory

13) Government funding for AT and its sharing by the community

14) Raise awareness to educate and encourage older people to use AT

\section{Acknowledgement}

This research is co-funded by the Economic and Social Research Council (ESRC), UK; L'Agence Nationale de la Recherche (ANR), France; and National Science Foundation of China (NSFC), China. We would like to thank all the experts who took the time to contribute to this research with their valuable insight and knowledge.

\section{References}

Agile Ageing Alliance. (2017). Neighbourhoods of the Future: Better Homes for Older Adults - Improving Health, Care, Design and Technology. London: A Creative Skills for Life Production. 
Best, R., \& Porteus, J. (2016). HAPPI 3 Housing our ageing population: Positive Ideas- Making Retirement Living A Positive Choice. London: All Party Parliamentry Group on Housing and Care for Older People.

China Health and Retirement Longitudinal Study. (2013). Retrieved from China Health and Retirement Longitudinal Study (CHARLS): http://charls.pku.edu.cn/en

Dahlan, A., \& Sultanlbrahim, S. A. (2017). An Activity Program for Older People. Asian Journal of Quality of Life AjQoL, 2(6), 1-10.

Davey, J., de Joux, V., Nana, G., \& Arcus, M. (2004). Accommodation options for older people in Aotearoa/New Zealand. Christchurch: . Christchurch: Centre for Housing Research Aotearoa/New Zealand (CHRANZ).

Faith, V., Hadjri, K., Rooney, C., Craig, C., \& McAllister, K. (2015). Finding a way: long-term care homes to support dementia. Proceedings of the Institution of Civil Engineers: Urban Design and Planning, 168(DP4), 204-217.

Feng, W. (2014). The Silver and White Economy: The Chinese Demographic Challenge. In OECD, Fostering resilient economies: demographic transition in local labour markets. Secretary-General of the OECD. Retrieved from https://www.oecd.org/employment/leed/OECD-China-report-Final.pdf

Gupta, R., Barnfield, L., \& Gregg, M. (2017). Overheating in care settings: magnitude, causes, preparedness and remedies. Building Research \& Information, 45(1-2), 83-101.

HACT. (2016). Is housing really ready to go digital? A manifesto for change. London: HACT.

Hadjri, K., Afacan, Y., \& Gadakari, T. (2016). Inclusive Design. In M. Noguchi, ZEMCH: Toward the Delivery of Zero Energy Mass Custom Homes (pp. 151-173). Switzerland: Springer.

Hussein, H., Omar, Z., \& Ishak, S. A. (2016). Sensory Garden for an Inclusive Society. Asian Journal of Behvioural Studies AjBeS, 1(4), 33-43.

Iwarsson, S., \& A, S. (2003). Accessibility, usability and universal design--positioning and definition of concepts describing person-environment relationships. Disability and rehabilitation, 25(2), 57-66.

Lawler, K. (2001). Aging in Place: Coordinating Housing and Health Care Provision for America's Growing Elderly Population. Washington: Joint Center for Housing Studies of Harvard University \& Neighbourhood Reinvestment Corporation.

Li, B. (2010). Polarisation and features: The living arrangement of Chinese older people. Chinese Journal of Population Science, 2010(2), 101-112.

Ministry of Housing and Urban-Rural Development of People's Republic of China (MOHURD) \& General Administration of Quality Supervision, Inspection and Quarantine of the People's Republic of China (AQSIQ). (2017). Code for design of residential building for the aged. Beijing: China Architecture \& Building Press.

Muhammad, Z. (2016). Community- Based Projects in Nigeria. Asian Journal of Quality of Life AjQoL, 1(4), 11-21.

National Bureau of Statistics of the People's Republic of China. (2016). The public service needs research based on home-based care model. Retrieved from National Bureau of Statistics of the People's Republic of China, Zhejiang investigation team: http://www.zhejiang.gov.cn/art/2016/5/30/art_5499_2125063.html

OECD. (2014). Fostering Resilient Economies: Demographic Transition in Local Labour Markets. Secretary-General of the OECD. 
Pannell, J., \& Blood, I. (2012). Supported Housing for Older People in the UK: An Evidence Review. London: Joseph Rowntree Foundation.

Renaut, S., Ogg, J., Petite, S., \& Chamahian, A. (2015). Home environments and adaptations in the context of ageing. Ageing and Society, 35(6), 1278-1303.

Roelofsen, P. (2014). Healthy ageing - Design criteria for the indoor environment for vital elderly. Intelligent Buildings International, 6(1), 11-25.

Stones, D., \& Gullifer, J. (2016). 'At home it's just so much easier to be yourself': older adults' perceptions of ageing in place. Ageing and Society, 36(3), 449-481.

Torrington, J. (2014). Future of an ageing population: evidence review. London: Foresight, Government Office for Science.

Twyford, K. (2016). Individuals with dementia living in extra care housing: an initial exploration of the practicalities and possibilities. London: Housing Learning \& Information Network.

United Nations. (2013). World Population Prospects: The 2012 Revision Population Database. New York: United Nations.

Walker, M. (2017). Creating homes that people would like to live in rather than have to live in: Is there a role for occupational therapists in the design of housing? London: Housing Learning \& Improvement Network.

World Health Organisation. (2011). Global Health and Aging. National Institute on Aging, National Institutes of Health, World Health Organisation.

World Health Organization. (2007). Global Age-Friendly Cities Project: A Guide. Geneva: WHO Press.

Yousefi, Z., Hosseini, S.-B., Yazdanfar, S.-A., \& Norouzian-Maleki, S. (2017). Promoting the Residents' Sense of Belonging in Housing Design. Asian Journal of Behavioural Studies AjBeS, 2(5), 33-43.

Zakariya, K., Harun, N. Z., \& Mansor, M. (2016). Space and Sociability: Mapping Melbourne's City Square. Asian Journal of Quality of Life AjQoL, 1(2), 45-55.

Zhang, J., Liu, H., \& Qi, Y. (2015). Living environment and life satisfaction of aged population in Beijing Municipality. Progress In Geography, 34(12), 1628- 1636.

Zhou, J., \& Walker, A. (2016). The need for community care among older people in China. Ageing \& Society, 36(6), 1312-1332. 


\section{Appendix}

List of Interview Questions:

Q1) From your experience of designing for older people, what would be the major design factors to consider that can support their ageing-in-place needs? Can you prioritise these factors according to your opinion?

Q2) Are you aware of any specific standards, or design guidelines for older people's living environment? During your design process, do you refer to them? How important do you think these standards or design guidelines are?

Q3) Are you aware of government policies regarding the ageing industry in China? Do these policies influence or guide your design project in any way?

Q4) According to research data, many older people are currently living in overcrowded conditions in China. In your opinion, is it possible to change this situation by designing in a more efficient way (architectural/interior design)? Can you provide any examples?

Q5) In China, some older people are currently living with their children or even grandchildren. From your point of view, is it possible to better support multi-generational living by means of architectural design? Can you provide any examples?

Q6) Meanwhile, there are also some older people who choose to live alone or with their partners in order to not put much pressure on their children. How do you think we can support these older people through design?

Q7) While conducting refurbishment or reconstruction, which elements or conditions of the existing environment could potentially become design barriers?

Q8) In the housing projects, how could the design better adapt to current residents' future needs as they get older?

Q9) How do you think financial affordability affects older people's decision to refurbish, reconstruct and adapt their homes?

Q10) In your opinion, how to reflect human-centred care through housing design? How do you maintain the balance between human-centred care and the value of design? Can you provide any examples?

Q11) How to maximise the feeling of home through the use of architecture/interior design in care home settings? Can you provide any examples?

Q12) Are you aware of any assistive technology which can provide or is providing support to older people so as to create a more independent, healthy, and safe living environment?

Q13) Do you think community care is important for ageing? In what way can the design of community affect older people's everyday lives?

Q14) What is your understanding of ageing-in-place? In your opinion, why do you think older people in China prefer to age-in-place? 